\title{
Evaluation of the Knowledge and Perceptions of Patients towards Generic Medicines in UAE
}

\author{
Suleiman I. Sharif*, Raneem J. Chaar, Zahraa Z. Albadrani, Jameel S. Shahwan, \\ Mohamed N. Badreddin, Mohamed A. K. Charbaji
}

Department of Pharmacy Practice and Pharmacotherapeutics, College of Pharmacy, University of Sharjah, Sharjah, United Arab Emirates

Email: *sharifsi@sharjah.ac.ae

How to cite this paper: Sharif, S.I., Chaar, R.J., Albadrani, Z.Z., Shahwan, J.S., Badreddin, M.N. and Charbaji, M.A.K. (2016) Evaluation of the Knowledge and Perceptions of Patients towards Generic Medicines in

UAE. Pharmacology \& Pharmacy, 7, 369378

http://dx.doi.org/10.4236/pp.2016.79045

Received: August 11, 2016

Accepted: August 29, 2016

Published: September 1, 2016

Copyright $\odot 2016$ by authors and Scientific Research Publishing Inc.

This work is licensed under the Creative Commons Attribution International License (CC BY 4.0).

http://creativecommons.org/licenses/by/4.0/

\begin{abstract}
Objectives: The objective of this study was to evaluate the knowledge and perceptions of patients towards generic medicines in some Emirates of the United Arab Emirates. Methods: A cross-sectional survey involving patients in three Emirates was undertaken. A 23-item questionnaire was designed, pre-validated and administered. Results: The questionnaire was fully answered by 96 patients out of 120 producing a response rate of $80 \%$. The majority of patients were young Arab females with a university degree. Slightly less than $50 \%$ of patients were having a monthly income of less than ED 10,000. Results of the patient's survey indicate that they have poor knowledge and perception of generic medicines. They did not know the meaning of generic or brand medicines and this negatively influenced their responses to consequent questions. Conclusion: Patients' knowledge and perception of generic drugs were poor. Efforts are needed to increase public awareness of generic drugs and possible brand substitution. Both the prescribing physician and the dispensing pharmacists have an essential role to play in educating their patients of generic drugs.
\end{abstract}

\section{Keywords}

Evaluation, Patients, Generic Medicines, Brand Medicines, Knowledge, Perception

\section{Introduction}

Generic medicine use is increasing both in developing and developed countries. Prescribing trends among physicians can be investigated using the drug use indicators suggested by the World Health Organization (WHO) [1]. In a previous study of this kind, we demonstrated that generic prescribing by both consultants and general practi- 
tioners in the United Arab Emirates was far from ideal [2]. However, there is evidence that not only doctors but also pharmacists hold negative views of generics and resist prescribing generic medicines [3] [4]. Patients have been shown to have poor knowledge and misconceptions about generic medicines [5]. Many studies have reported patients to have negative views about generics as they believe generics to be less effective, of lower quality and unsuitable for treatment of major illnesses, as compared to their branded equivalents [5]-[7]. It is worth noting that some patients might ask the prescriber for a particular drug by name which is usually brand and expensive drug either because of previous experience with the medicine or due to the impact of promotional activity. It has also been suggested that such an insistence on an expensive medicine may be because the patient does not pay the full cost or because they believe that those drugs are better than cheaper ones [8]. Keeping this in mind, it seems rather important to evaluate the level of knowledge, perception and attitudes of patients and if the levels are poor or misconception were of significant negative impact on generics use, interventions must be implemented to increase awareness of the public towards generic drugs as substitutes for expensive counterpart brands. It must be noted that low income patients and those without medical insurance coverage may not adhere to their prescribed drugs if they cannot afford its cost and as such drug compliance may not be achieved and this would negatively impact therapeutic outcomes. On the other hand, prescribing generic medicine by the physician or replacement of brand by generic by the pharmacist would have the opposite effect. Taken cost of medicine into consideration, it must be remembered that generics, according to estimates of Food and Drug Administration (FDA) are usually 20\% - 70\% less expensive than their counterpart brands [9]. In the United Arab Emirates (UAE) there is a lack of studies on generic prescribing and knowledge, perception and attitude of patients towards generic drugs. Therefore, this study was undertaken to evaluate the level of knowledge, perception and attitude of patients towards generic versus brand medicines.

\section{Methods}

\subsection{Questionnaire and Study Design}

We designed a questionnaire to collect data on patient's knowledge and perception of generic drugs that was prepared both in Arabic and in English (available upon request) and pre-piloted by distributing to six patients who were randomly selected and interviewed face-to-face and their recommendations, comments and views were taken into consideration in the final version of the survey. Patient inclusion criteria include patients, who willingly accepted to participate in the survey and thought capable of responding to the questionnaire. We targeted patients attending private clinics, public hospitals, and health centers in the Emirates of Abu Dhabi, Sharjah and Ajman, UAE during the months of February-March, 2016. A total of 120 questionnaires were distributed to patients. Once the returned questionnaires were subjected to analysis, only 96 questionnaires were completely filled and their responses were considered in the results. Patient's participation was totally voluntary and their informed consent was obtained. 
In addition to that, anonymity of respondents in the study was preserved in which the names of participants were not included. One of the investigators was available during filling the questionnaire to clarify any queries. The questionnaire consisted of three sections. The first dealt with patient's demographic data including gender, age, ethnic group, educational level, monthly income, medical insurance and \% cost paid per prescription. The second section comprised the average number of prescriptions per year, practice of self-medication without prescription, asking for specific medicine by name, explaining the condition and consulting the pharmacist for medication and whether the patient prefers local or imported medicines. We also examined patient's believes of imported medicines as compared to locally produced drugs. Patients have to select either agree, not sure or disagree to statements on whether imported medicines are of higher quality, more effective, more expensive, with less side effects, more prescribed by physicians, more recommended by dispensing pharmacists and are more advertised than locally produced drugs.

In the third part of the questionnaire, we examined the patient's knowledge and perception of generic medicines. In this section, patients were asked if they know the meaning of generic and brand medicines, and to briefly describe each in case they know, and if they think there are differences between generic and brand medicines. In addition, patients were asked whether they agree, are not sure or disagree to statements such as; brand medicines are of higher quality than generics, safer, with fewer side effects and whether they are more expensive. Patients were also asked whether they accept substitution by pharmacists of their prescribed brand with generic and what generics they prefer locally produced or imported, cheap or expensive, and how often their brand medication was replaced by a generic one and whether the cost of the prescribed medicines is an issue or not as long as his/her condition is treated.

\subsection{Statistical Analysis}

Responses of the participants were encoded and the data were analyzed using Statistical Package for the Social Sciences (SPSS, version 17, Chicago, IL, US). Three categories of the relevant responses were used so that $95 \%$ confidence intervals (95\% CI) could be calculated. Descriptive analysis was used to calculate the proportion of each group of respondents who agreed/disagreed with each statement in the questionnaire. Chi square test was used to identify any significant difference among the participants' responses regarding certain statements in the questionnaire with a significant level of $p$ value of $<0.05$.

\section{Results}

Participants include more female $(71,74 \%)$ than male $(25,26 \%)$ patients. More than two thirds of participants were young (20 - 30 years) Arabs and holders of a university degree. Slightly less than $50 \%$ of the participants were with a monthly income of less than ED 10,000 (Table 1).

Views of patients on imported drugs as compared to locally produced medicines are 
Table 1. Demographic characteristics of patients.

\begin{tabular}{|c|c|}
\hline Criteria & Frequency $(\%) n=96$ \\
\hline \multicolumn{2}{|l|}{ Gender } \\
\hline Male & $25(26 \%)$ \\
\hline Female & $71(74 \%)$ \\
\hline \multicolumn{2}{|l|}{ Age } \\
\hline $20-30$ & $65(67.7 \%)$ \\
\hline $31-40$ & $14(14.6 \%)$ \\
\hline $41-50$ & $12(12.5 \%)$ \\
\hline $51-60$ & $4(4.2 \%)$ \\
\hline$>60$ & $1(1.1 \%)$ \\
\hline \multicolumn{2}{|l|}{ Nationality } \\
\hline Arabic & $77(80.2 \%)$ \\
\hline Non-Arabic & $18(18.8 \%)$ \\
\hline \multicolumn{2}{|l|}{ Educational level } \\
\hline Illiterate & $8(8.3 \%)$ \\
\hline High school & $6(6.3 \%)$ \\
\hline University degree & $73(76 \%)$ \\
\hline Master & $4(4.2 \%)$ \\
\hline Ph.D. & $5(5.2 \%)$ \\
\hline \multicolumn{2}{|c|}{ Patient's monthly income ED } \\
\hline$<1000$ & $47(49 \%)$ \\
\hline $10,000-14,000$ & $20(20.8 \%)$ \\
\hline $15,000-19,000$ & $14(14.6 \%)$ \\
\hline $20,000-24,000$ & $12(12.5 \%)$ \\
\hline $25,000-30,000$ & $3(3.1 \%)$ \\
\hline
\end{tabular}

shown in Table 2. The majority of patients agreed to the statements that imported medicines are of higher quality (44.8\%), more effective (50\%), more expensive 66.7\%), more advertised (65.6\%) and more prescribed (42\%) than locally produced drugs. Knowledge of participants of brand medicines as compared to generics is shown in Table 3. It is clear that knowledge of patients in the present study is poor as $47 \%-50 \%$ of the data that is based on awareness of brand and generic medicines was not recorded by participants.

Fifty six $(58.3 \%)$ of female and $14(14.6 \%)$ of male patients did not know what is meant by generic or brand name medicines while more females $(15,15.6 \%)$ than males $(11,11.5 \%)$ knew the meaning of both drug categories (Table 4). There was no statistical significance between males and females concerning their preference of locally 
Table 2. Views of patients on various aspects of imported versus locally produced drugs.

\begin{tabular}{|c|c|c|c|c|}
\hline \multirow{2}{*}{ Statement } & \multicolumn{3}{|c|}{ Frequency (\%), $\mathrm{n}=96$} & \multirow{2}{*}{$\begin{array}{l}\text { 95\% CI for Agree } \\
\text { responses }\end{array}$} \\
\hline & Agree & Not sure & Disagree & \\
\hline Imported medicines are of higher quality & $43(44.8 \%)$ & $41(42.7 \%)$ & $41(42.7 \%)$ & $(34.89-54.69)$ \\
\hline Imported medicines are more effective & $48(50 \%)$ & $36(37.5 \%)$ & $12(12.5 \%)$ & $(40.05-59.95)$ \\
\hline Imported medicines are more expensive & $64(66.7 \%)$ & $22(22.9 \%)$ & $10(310.4 \%)$ & $(57.28-76.05)$ \\
\hline Imported medicines produce fewer side effects & $18(18.8 \%)$ & $43(44.8 \%)$ & $35(36.5 \%)$ & $(10.98-26.52)$ \\
\hline $\begin{array}{l}\text { Imported medicines are more } \\
\text { prescribed by physicians }\end{array}$ & $42(43.8 \%)$ & $42(43.8 \%)$ & $11(11.5 \%)$ & $(33.88-53.62)$ \\
\hline $\begin{array}{l}\text { Imported medicines are recommended } \\
\text { more by pharmacists }\end{array}$ & $33(34.4 \%)$ & $45(46.9 \%)$ & $17(17.7 \%)$ & $(24.92-43.83)$ \\
\hline Imported medicines are more advertised & $63(65.6 \%)$ & $23(24 \%)$ & $10(10.4 \%)$ & $(56.17-75.08)$ \\
\hline
\end{tabular}

Table 3. Patient's knowledge of properties of brand as compared to generic medicines.

\begin{tabular}{|c|c|c|c|c|c|}
\hline \multirow[b]{2}{*}{ Statement } & \multicolumn{4}{|c|}{ Frequency (\%), $n=96$} & \multirow{2}{*}{$\begin{array}{l}\text { 95\% CI for } \\
\text { agree } \\
\text { responses }\end{array}$} \\
\hline & Agree & Not sure & Disagree & $\begin{array}{l}\text { Data not } \\
\text { recorded }\end{array}$ & \\
\hline Quality of brand medicine is higher. & $26(27.1 \%)$ & $12(12 \%)$ & $13(13.5 \%)$ & $45(46.9 \%)$ & $(18.24-35.93)$ \\
\hline Brand medicine is more effective. & $21(21.9 \%)$ & $13(13.5 \%)$ & $15(15.6 \%)$ & $47(49 \%)$ & $(13.65-30.10)$ \\
\hline Brand medicine is safer. & $18(18.8 \%)$ & $16(16.7 \%)$ & $15(15.6 \%)$ & 47 (49\%) & $(10.98-26.52)$ \\
\hline Brand medicine is more expensive. & $37(38.5 \%)$ & $9(9.4 \%)$ & $3(3.1 \%)$ & $47(49 \%)$ & $(28.86-48.23)$ \\
\hline $\begin{array}{l}\text { Brand medicine produces } \\
\text { fewer side effects. }\end{array}$ & $11(11.5 \%)$ & $21(21.9 \%)$ & $16(16.7 \%)$ & $48(50 \%)$ & $(5.12-17.80)$ \\
\hline
\end{tabular}

Table 4. Influence of patient's gender on various aspects of generic drugs.

\begin{tabular}{cccc}
\hline \multirow{2}{*}{ Question/statement } & \multicolumn{2}{c}{ Gender, frequency (\%), $\mathbf{n}=96$} \\
\cline { 2 - 3 } Yes & Male & Female & P value \\
No & $11(11.5 \%)$ & $15(15.6 \%)$ & 0.028 \\
Do you know what is meant by generic medicines? & $14(14.6 \%)$ & $56(58.3 \%)$ & \\
Yes & & \\
No & $13(13.5 \%)$ & $16(16.7 \%)$ & 0.007 \\
Do you know what is meant by brand medicines? & $12(12.5 \%)$ & $55(57.3 \%)$ & \\
Locally produced & & \\
Imported & $13(13.5 \%)$ & $40(41.7 \%)$ & 0.056 \\
Which generic medicine you prefer? & $12(12.5 \%)$ & $31(32.1 \%)$ \\
Cost is not an issue as long as my condition is treated. & & \\
Yes & $25(26 \%)$ & $49(51 \%)$ & 0.062 \\
No & 0 & $22(22.9 \%)$
\end{tabular}

Chi square test, significance at $\mathrm{p}$ value $<0.05$. 
produced or imported generics. When considering the cost, statistically significant number of females selected yes to cost being not an issue as long as their condition is treated. Although low $(21,21.9 \%)$ but statistically significant number of the youngest (20 - 30 years) age group agreed that brand medicines are more expensive than generics (Table 5). More Arab (65, 67.7\%) than non-Arab patients (4, 4.2\%) did not know what is meant by brand or generic. However, only less than $5 \%$ of non-Arab pharmacists did not know the meaning of both brand and generic medicines (Table 6). When asked whether more imported medicines are recommended by pharmacists, about one third of Arab patients agreed or was not sure. With regard to the statement that imported medicines produce fewer side effects than locally produced ones, statistically higher percentages of Arab patients disagreed or were not sure of such statement (Table 3). In studying the influence of the level of education on the statements that brands are more recommended by pharmacists and being more expensive than generics, statistically significant higher percentages of patients with a master degree approved both statements (Table 7). The monthly income of patients did not statistically influence their preference to locally produced or imported drugs but patients with the least monthly income $(<10,000 \mathrm{ED})$ agreed or were not sure of imported medicines being of higher quality, more effective and are more prescribed by physicians than locally produced counterparts (Table 8).

\section{Discussion}

In the present study, most of the participants were young Arab females with a university degree who believed that imported drugs are superior to locally manufactured counterparts. In addition, knowledge of patients of generic and brand medicines was rather poor and this was negatively reflected on their consequent responses to the questions in the survey. In general, patients have less confidence in generic drugs, because, among other reasons, the packaging of generics does not have acceptable appearance as brand drugs do. It has been reported that a significant disadvantage to the use of genericsand a factor identified as conducive to continued use of proprietary medicines-was variability in appearance of generics [10]. Also some patients insist on certain drugs, because of their previous experience or due to the impact of promotional activity in favor of these drugs. Knowledge of patients in the present study was poor as compared to

Table 5. Influence of patient's age on whether brand medicine is more expensive than generic ones.

\begin{tabular}{ccccccc}
\hline \multirow{2}{*}{ Statement } & \multicolumn{5}{c}{ patient age (years), frequency (\%), $\mathrm{n}=96$} \\
\cline { 2 - 7 } & $20-30$ & $31-40$ & $41-50$ & $51-60$ & $>60$ & P value \\
\hline $\begin{array}{c}\text { Brand medicines are more } \\
\text { expensive than generics. }\end{array}$ & $21(21.9 \%)$ & $8(8.3 \%)$ & $6(6.3 \%)$ & $2(2.1 \%)$ & 0 & \\
Agree & $8(8.3 \%)$ & 0 & $1(1 \%)$ & 0 & 0 & 0.005 \\
Not sure & 0 & $1(1 \%)$ & $1(1 \%)$ & 0 & $1(1 \%)$ \\
Disagree & & & & & & \\
\hline
\end{tabular}

Chi square test, significance at $\mathrm{p}$ value $<0.05$. 
Table 6. Influence of ethnicity of patient on some aspects of generic medicines.

\begin{tabular}{|c|c|c|c|}
\hline \multirow{2}{*}{ Questions/statement } & \multicolumn{3}{|c|}{ Frequency (\%), n = 96} \\
\hline & Arabic & Non-Arabic & ${ }^{*} \mathrm{P}$ value \\
\hline \multicolumn{4}{|c|}{ Do you know what is meant by generic medicines? } \\
\hline Yes & $12(12.5 \%)$ & $14(14.6 \%)$ & 0.000 \\
\hline No & $65(67.7 \%)$ & $4(4.2 \%)$ & \\
\hline \multicolumn{4}{|c|}{ Do you know what is meant by brand medicines? } \\
\hline Yes & $15(15.6 \%)$ & $14(14.6 \%)$ & 0.000 \\
\hline No & $62(64.6 \%)$ & $4(4.2 \%)$ & \\
\hline \multicolumn{4}{|c|}{$\begin{array}{l}\text { Imported medicines are recommended } \\
\text { more by pharmacists. }\end{array}$} \\
\hline Agree & $30(31.3 \%)$ & $2(2.1 \%)$ & 0.072 \\
\hline Not sure & $33(34.4 \%)$ & $12(12.5 \%)$ & \\
\hline Disagree & $14(14.6 \%)$ & $3(3.1 \%)$ & \\
\hline \multicolumn{4}{|c|}{$\begin{array}{l}\text { Imported medicines produce fewer side effects } \\
\text { than locally produced ones. }\end{array}$} \\
\hline Agree & $16(16.7 \%)$ & $2(2.1 \%)$ & 0.038 \\
\hline Not sure & $30(31.3 \%)$ & $13(13.5 \%)$ & \\
\hline disagree & $31(32.3 \%)$ & $3(3.1 \%)$ & \\
\hline
\end{tabular}

Chi square test, significance at $\mathrm{p}$ value $<0.05$.

Table 7. Views on imported and brand medicines.

\begin{tabular}{|c|c|c|c|c|c|c|}
\hline \multirow{2}{*}{ Questions/statement } & \multicolumn{6}{|c|}{ Frequency (\%), n = 96} \\
\hline & Illiterate & High school & University & Master & Ph.D. & ${ }^{*} \mathrm{P}$ value \\
\hline \multicolumn{7}{|c|}{$\begin{array}{l}\text { Imported medicines are } \\
\text { recommended more by pharmacists }\end{array}$} \\
\hline Agree & $2(2.1 \%)$ & $1(1 \%)$ & $27(28.1 \%)$ & $3(3.1 \%)$ & 0 & 0.009 \\
\hline Not sure & $4(4.2 \%)$ & $1(1 \%)$ & $35(36.5 \%)$ & 0 & $5(5.2 \%)$ & \\
\hline Disagree & $2(2.1 \%)$ & $4(4.2 \%)$ & $10(10.4 \%)$ & $1(1 \%)$ & 0 & \\
\hline \multicolumn{7}{|l|}{$\begin{array}{l}\text { Brand medicines are more } \\
\text { expensive than generics }\end{array}$} \\
\hline Agree & $2(2.1 \%)$ & 0 & $30(31.3 \%)$ & $2(2.1 \%)$ & $3(3.1 \%)$ & 0.002 \\
\hline Not sure & 0 & $2(2.1 \%)$ & $7(7.3 \%)$ & 0 & 0 & \\
\hline Disagree & $2(2.1 \%)$ & 0 & $1(1 \%)$ & 0 & 0 & \\
\hline
\end{tabular}

Chi square test, significance at $\mathrm{p}$ value $<0.05$. 
Table 8. Influence of patient's monthly income on their views on some aspects of imported drugs.

\begin{tabular}{|c|c|c|c|c|c|c|}
\hline \multirow{2}{*}{$\begin{array}{l}\text { Question/ } \\
\text { statement }\end{array}$} & \multicolumn{6}{|c|}{ Frequency (\%), n = 96} \\
\hline & 10 & $10-14$ & $15-20$ & $20-24$ & $25-30$ & ${ }^{*} \mathrm{P}$ value \\
\hline \multicolumn{7}{|l|}{$\begin{array}{l}\text { What medicines } \\
\text { do you prefer? }\end{array}$} \\
\hline -Locally produced & $7(7.3 \%)$ & $8(8.3 \%)$ & $2(2.1 \%)$ & $1(1 \%)$ & 0 & 0.064 \\
\hline -Imported & $18(18.8 \%)$ & $6(6.3 \%)$ & $3(3.1 \%)$ & $5(5.2 \%)$ & $3(3.1 \%)$ & \\
\hline No preference & $22(22.9 \%)$ & $6(6.3 \%)$ & $9(9.4 \%)$ & $6(6.3 \%)$ & 0 & \\
\hline \multicolumn{7}{|c|}{$\begin{array}{l}\text { Imported medicines are of } \\
\text { higher quality than local ones. }\end{array}$} \\
\hline Agree & $16(16.7 \%)$ & $14(14.6 \%)$ & $6(6.3 \%)$ & $4(4.2 \%)$ & $3(3.1 \%)$ & 0.005 \\
\hline Not sure & $27(28.1 \%)$ & $4(4.2 \%)$ & $3(3.1 \%)$ & $7(7.3 \%)$ & 0 & \\
\hline Disagree & $4(4.2 \%)$ & $2(2.1 \%)$ & $5(5.2 \%)$ & $1(1 \%)$ & 0 & \\
\hline \multicolumn{7}{|l|}{$\begin{array}{l}\text { Imported medicines } \\
\text { are more effective. }\end{array}$} \\
\hline Agree & $18(18.8 \%)$ & $14(14.6 \%)$ & $8(8.3 \%)$ & $5(5.2 \%)$ & $3(3.1 \%)$ & 0.009 \\
\hline Not sure & $24(25 \%)$ & $5(5.2 \%)$ & $1(1 \%)$ & $6(6.3 \%)$ & 0 & \\
\hline Disagree & $5(5.2 \%)$ & $1(1 \%)$ & $5(5.2 \%)$ & $1(1 \%)$ & 0 & \\
\hline \multicolumn{7}{|c|}{$\begin{array}{l}\text { Physicians prescribe } \\
\text { mainly imported medicines }\end{array}$} \\
\hline Agree & $21(21.9 \%)$ & $11(11.5 \%)$ & $2(2.1 \%)$ & $7(7.3 \%)$ & $2(2.1 \%)$ & 0.019 \\
\hline Not sure & $23(24 \%)$ & $4(4.2 \%)$ & $8(8.3 \%)$ & $5(5.2 \%)$ & 0 & \\
\hline Disagree & $2(2.1 \%)$ & $5(5.2 \%)$ & $4(4.2 \%)$ & 0 & 0 & \\
\hline
\end{tabular}

Chi square test, significance at $\mathrm{p}$ value $<0.05$.

that of renal patients in $\mathrm{Al}$ Ain Emirate-UAE [11]. However, even in the later study, some of highly educated patients were unsure of the efficiency of generic medicines and substitution [11]. In addition, pharmacists may not promote generics as this may negatively affect their sales. Both physicians and pharmacists, who have direct contact with the patients, should be more convinced that generic drugs can have as good quality as brands. Also they themselves should be educated that brand drugs are not necessarily of higher and better quality than generics. Moreover, for the benefit of the patients, more effective communication between the treating physician and the community pharmacist should be established. We have earlier shown that $60 \%$ of physicians rarely or never discuss patient's drug therapy with the pharmacist [12]. The present patients' poor ability to differentiate between generic and brand drugs, could improve tremendously if both the pharmacists and the physicians focus on communicating more with their patients, educate them about the correct selection between generic and brand drugs and inform them that both categories of medicines have similar effectiveness but generics are cheaper. It is also a fact that some patients are with the wrong impression that the 
more expensive the medication, the better its quality and its effectiveness [13].

\section{Conclusion}

Results of this survey conclude lack of knowledge of generic medicines and patients are inclined to prefer imported drugs. Efforts must be directed towards increasing public awareness of generic medicines and should also focus on educating physicians and pharmacists about generic medicines through inclusion of related topics in undergraduate curricula and continuing educational programs.

\section{Acknowledgements}

The authors are greatly indebted to all patients who participated in the study.

\section{Limitation of the Study}

In the present study although we covered patients from three Emirates in UAE, coverage of patients from other Emirates would produce more informative results particularly in the light of the relatively small sample size of our study.

\section{Conflict of Interest}

The authors declare that there is no conflict of interest.

\section{References}

[1] Sharif, S.I., Fazli, H., Tajrobehkar, Y., Namvar, Z. and Bugaighis, L.M.T. (2015) Drug Prescribing Trends among Consultants and General Practitioners in Sharjah-UAE. Pharmacology \& Pharmacy, 6, 374-379. http://dx.doi.org/10.4236/pp.2015.68038

[2] WHO (1995) How to Investigate Drug Use in Health Facilities: Selected Drug Use Indicators. World Health Organization, Geneva, WHO/DAP/93.1.1995.

[3] Chong, C.P., Hassali, M.A., Bahari, M.B. and Shafie, A.A. (2011) Exploring Community Pharmacists' Views on Generic Medicines: A Nationwide Study from Malaysia. International Journal of Clinical Pharmacy, 33, 124-131.

http://dx.doi.org/10.1007/s11096-010-9470-1

[4] Shrank, W.H., Liberman, J.N., Fischer, M.A., Girdish, C., Brennan, T.A. and Choudhary, N.K. (2011) Physician Perceptions about Generic Drugs. Annals of Pharmacotherapy, 45, 31-38. http://www.ncbi.nlm.nih.gov/pubmed/21205953 http://dx.doi.org/10.1345/aph.1p389

[5] Al Ameri, M.N., Whittaker,C., Tucker, A. and Johnston, A. (2011) A Survey to Determine the Views of Renal Transplant Patients on Generic Substitution in the UK. Transplant International, 24, 770-779. www.ncbi.nlm.nih.gov/pubmed/21575080 http://dx.doi.org/10.1111/j.1432-2277.2011.01268.x

[6] Himmel, W., Simmenroth-Nayda, A., Niebling, W., Ledig T., Jansen, R.D., Kochen, M.M., Gleiter, C.H. and Hummers-Pradier, E. (2005) What Do Primary Care Patients Think about Generic Drugs? International Journal of Clinical Pharmacology and Therapeutics, 43, 472479. www.academia.edu/17656190/What do primary $c$

[7] Faasse, K., Cundy, T., Gamble, G. and Petrie, K.J. (2013) The Effect of an Apparent Change to a Branded or Generic Medication on Drug Effectiveness and Side Effects. Psychosomatic 
Medicine, 75, 90-96. www.ncbi.nlm.nih.gov/pubmed/23115341

http://dx.doi.org/10.1097/psy.0b013e3182738826

[8] Quintala, C. and Mendesb, P. (2012) Underuse of Generic Medicines in Portugal: An Empirical Study on the Perceptions and Attitudes of Patients and Pharmacists. Health Policy, 104, 61-68. http://www.healthpolicyjrnl.com/article/S0168-8510(11)00199-0/abstract? cc=y= http://dx.doi.org/10.1016/j.healthpol.2011.10.001

[9] Food \& Drug Administration. Facts about Generic Drugs. http://www.fda.gov/Drugs/ResourcesForYou/Consumers/BuyingUsingMedicineSafely/Und erstandingGenericDrugs/ucm 167991.htm

[10] World Health Organization (2003) Introduction to Drug Utilization Research. WHO, Oslo. http://apps.who.int/medicinedocs/en/d/Js4876e/

[11] Al Ameri, M.N., Mohamed, W., Makramalla, E., Shalhoub, B., Tucker, A. and Johnston, A. (2013) Renal Patients' Views on Generic Prescribing and Substitution: Example from the United Arab Emirates. Eastern Mediterranean Health Journal, 19, 373-381. www.ncbi.nlm.nih.gov/pubmed/23882964

[12] Abduelkarem, A.R. and Sharif, S.I. (2008) Current Levels of Interaction between the Physician and Pharmacist: A Comparative Study in Libya and UAE. Jordan Journal of Pharmaceutical Sciences, 1, 142-150. http://journals.ju.edu.jo/JJPS/issue/archive

[13] Meredith, P. (2003) Bioequivalence and Other Unresolved Issues in Generic Drug Substitution. Clinical Therapeutics, 25, 2875-2890. www.ncbi.nlm.nih.gov/pubmed/14693311

\section{Submit or recommend next manuscript to SCIRP and we will provide best service for you:}

Accepting pre-submission inquiries through Email, Facebook, LinkedIn, Twitter, etc.

A wide selection of journals (inclusive of 9 subjects, more than 200 journals)

Providing 24-hour high-quality service

User-friendly online submission system

Fair and swift peer-review system

Efficient typesetting and proofreading procedure

Display of the result of downloads and visits, as well as the number of cited articles

Maximum dissemination of your research work

Submit your manuscript at: http://papersubmission.scirp.org/ 